\title{
A stability study of impregnated LSCF-GDC composite cathodes of solid oxide fuel cells
}

\author{
Yihui Liu ${ }^{\mathrm{ab}}$, Fangzhong Wang ${ }^{\mathrm{a}}$, Bo Chi ${ }^{\mathrm{a} *}$, Jian Pu ${ }^{\mathrm{a}}$, Li Jian ${ }^{\mathrm{a}}$, San Ping Jiang ${ }^{\mathrm{b} *}$ \\ ${ }^{a}$ Center for Fuel Cell Innovation, School of Materials Science and Engineering, State Key \\ Laboratory of Material Processing and Die \& Mould Technology, Huazhong University of \\ Science and Technology, Wuhan 430074, PR China \\ ${ }^{\mathrm{b}}$ Fuels and Energy Technology Institute \& Department of Chemical Engineering, Curtin \\ University, Perth, WA 6102, Australia
}

\begin{abstract}
The performance degradation of composite cathodes of $\mathrm{La}_{0.6} \mathrm{Sr}_{0.4} \mathrm{Co}_{0.2} \mathrm{Fe}_{0.8} \mathrm{O}_{3-\delta}$ and Gd-doped ceria (LSCF-GDC), prepared by impregnating the porous GDC scaffold with a nitrate solution containing $\mathrm{La}, \mathrm{Sr}, \mathrm{Co}$ and $\mathrm{Fe}$ in desired composition, is investigated at $750{ }^{\circ} \mathrm{C}$ and open circuit in air for 500 hrs. The performance of the impregnated LSCF-GDC composite cathodes deteriorates after testing at $750^{\circ} \mathrm{C}$ for $500 \mathrm{hrs}$; the electrode polarization resistance $\left(R_{\mathrm{p}}\right)$ increases from 0.38 to $0.83 \Omega \mathrm{cm}^{2}$, and the electrode ohmic resistance $\left(R_{\mathrm{o}}\right)$ increases from 1.79 to $2.14 \Omega \mathrm{cm}^{2}$. The grain growth and coarsening of impregnated LSCF nanoparticles are responsible for the performance degradation of the cathodes. XPS analysis shows the enrichment of cobalt on the surface of the infiltrated LSCF-GDC cathodes and such surface segregation could also contribute to the degradation of the electrocatalytic activity of the cathodes. Introducing $\mathrm{MgO}$ and $\mathrm{LaNi}_{0.6} \mathrm{Fe}_{0.4} \mathrm{O}_{3}$ phases can effectively suppress

*Corresponding authors.

Email: chibo@hust.edu.cn (B. Chi), s.jiang@curtin.edu.au (S.P. Jiang)
\end{abstract}


the coarsening of LSCF nanoparticles and enhance the stability of the cathodes. However, the enhancing effect is related to the conductivity and electrocatalytic activity of the introduced phases.

Keywords: Solid oxide fuel cells; Degradation; Nano-structured LSCF-GDC cathodes; Impregnation; Microstructure coarsening.

\section{Introduction}

Performance degradation is one of the most important and critical issues in the development of solid oxide fuel cells (SOFCs) with high performance and high durability. $\mathrm{La}_{0.6} \mathrm{Sr}_{0.4} \mathrm{Co}_{0.2} \mathrm{Fe}_{0.8} \mathrm{O}_{3-\delta}$ (LSCF) perovskite oxides are extensively studied and used as cathodes of SOFCs because they have excellent mixed electronic and ionic conductivities and high electrocatalytic activity for the $\mathrm{O}_{2}$ reduction reactions at intermediate temperatures [1-8]. However, the technological development of LSCF cathodes is hampered by the high performance degradation of the LSCF cathode materials [9-11]. LSCF cathodes have high activity and conductivity because of enhanced oxygen vacancy formation associated with valence transformation of cobalt in the crystal lattice[12]. But depletion of Co under operating conditions could cause performance instability[13]. The degradation mechanism on the LSCF based electrodes has been extensively studied. The interdiffusion or solid state reaction between the cathode and electrolyte[14], strontium $(\mathrm{Sr})$ segregation $[10,15]$ and the coarsening of microstructure $[11,16]$ have been reported to be responsible for the performance degradation of LSCF cathodes. The introduction of Gd-doped ceria (GDC) to LSCF cathodes improved their electrochemical activity but probably had little effects on the 
performance stability $[17,18]$. GDC has also been introduced between the YSZ electrolyte and the cathode as a buffer layer to suppress degradation of LSCF cathodes caused by $\mathrm{Sr}$ migration $[3,19,20]$. The introduction of GDC buffer layer has been shown to improve the stability of LSCF cathodes[19].

Highly active cathodes can also be developed via nano-structured approach using the wet impregnation or infiltration method [21-23]. In this method, mixed electronic and ionic conductivity material such as LSCF is impregnated into the pre-formed and rigid porous electrolyte scaffold on the dense electrolyte, forming nano-structured electrodes with high electrochemical activity. This method has been used for the developments of LSCF impregnated GDC(LSCF-GDC) [24], LSCF impregnated YSZ (LSCF-YSZ)[25, 26] and impregnating GDC materials into LSCF scaffold [27] composite cathodes with a very low polarization resistance and high activity for the $\mathrm{O}_{2}$ reduction at intermediate temperatures. However, the stability of such impregnated LSCF nanoparticles in porous scaffold is particularly a concern under SOFC operating conditions due to the high tendency of the grain growth and agglomeration of nanoparticles at high temperatures[11, 26, 28].

In the present study, the performance stability of nano-structured LSCF-GDC composite cathodes is investigated with the purpose of understanding their degradation mechanisms under typical SOFC operating conditions. The electrochemical impedance spectra (EIS) and the microstructure characteristic of the nano-structured LSCF-GDC composite cathodes were determined and effect of introducing $\mathrm{MgO}$ and $\mathrm{LaNi}_{0.6} \mathrm{Fe}_{0.4} \mathrm{O}_{3}$ (LNF) phases on the performance and microstructure stability of the nano-structured LSCF-GDC composite cathodes was investigated. 


\section{Experimental}

Electrolyte substrates were fabricated from 8 mol\% $\mathrm{Y}_{2} \mathrm{O}_{3}$-doped $\mathrm{ZrO}_{2}$ powders (YSZ, Tosoh Corp.) by die pressing at $100 \mathrm{MPa}$, followed by sintering at $1500{ }^{\circ} \mathrm{C}$ for $6 \mathrm{hrs}$ in air. Polyvinyl alcohol (Sinopharm Chemical Reagent Co. Ltd.) was used as binder. The electrolyte disks were $20 \mathrm{~mm}$ in diameter and $1.2 \mathrm{~mm}$ in thickness. For preparing the porous GDC scaffold, $\mathrm{Gd}_{0.2} \mathrm{Ce}_{0.8} \mathrm{O}_{2}$ powders, which were synthesized by citrate method [29], were mixed with binders (terpineol solutions of $4 \mathrm{wt} \%$ ethocel) and ground to form a slurry. Then the GDC slurry was screen printed on to the YSZ substrate and sintered at $1200{ }^{\circ} \mathrm{C}$ in air for 2 hrs. The thickness of porous GDC layer was $\sim 15 \mu \mathrm{m}$ and an active electrode area was 0.5 $\mathrm{cm}^{2}$. A $0.5 \mathrm{~mol} \mathrm{~L}-1$ aqueous nitrate solution of LSCF was prepared by dissolving proper amount of $\mathrm{La}\left(\mathrm{NO}_{3}\right)_{3} \cdot 6 \mathrm{H}_{2} \mathrm{O}, \quad \mathrm{Sr}\left(\mathrm{NO}_{3}\right)_{2}, \quad \mathrm{Co}\left(\mathrm{NO}_{3}\right)_{2} \cdot 6 \mathrm{H}_{2} \mathrm{O}, \quad \mathrm{Fe}\left(\mathrm{NO}_{3}\right)_{3} \cdot 9 \mathrm{H}_{2} \mathrm{O}$ (Sinopharm Chemical Reagent Co. Ltd.) in distilled water. The solution was then impregnated into the porous GDC scaffold at room temperature by using a microsyringe, and followed by calcination at $800{ }^{\circ} \mathrm{C}$ in air for $1 \mathrm{hr}$. Loading of impregnated LSCF was obtained by measuring the weight gain of the impregnated samples $[30,31]$. The impregnation-calcination process was repeated to achieve the desired LSCF loading in the composite cathode. The loading of LSCF in this study was $3.3 \mathrm{mgcm}^{2}$, equivalent to $30 \mathrm{wt} \%$.

$\mathrm{MgO}$ and LNF phases were introduced into LSCF-GDC cathodes to enhance the performance stability. A $0.5 \mathrm{~mol} \mathrm{~L}-1$ aqueous solution of $\mathrm{Mg}\left(\mathrm{NO}_{3}\right)_{2} \cdot 6 \mathrm{H}_{2} \mathrm{O}$ (Sinopharm Chemical Reagent Co. Ltd.) was impregnated into LSCF-GDC cathodes followed by calcination at $800{ }^{\circ} \mathrm{C}$ in air for $1 \mathrm{hr}$. The loading of impregnated $\mathrm{MgO}$ in LSCF-GDC 
cathodes was $10 \mathrm{wt} \%$. The impregnation solution of LNF was prepared from aqueous solutions of $\mathrm{La}\left(\mathrm{NO}_{3}\right)_{3} \cdot 6 \mathrm{H}_{2} \mathrm{O}, \mathrm{Ni}\left(\mathrm{NO}_{3}\right)_{2} \cdot 6 \mathrm{H}_{2} \mathrm{O}$ and $\mathrm{Fe}\left(\mathrm{NO}_{3}\right)_{3} \cdot 9 \mathrm{H}_{2} \mathrm{O}$ (Sinopharm Chemical Reagent Co. Ltd.). A $0.5 \mathrm{~mol} \mathrm{~L}^{-1}$ precursor solution of LNF was impregnated into the as-prepared LSCF-GDC cathodes and the impregnated LNF loading was $15 \mathrm{wt} \%$. The LNF impregnated LSCF-GDC cathode was heat-treated at $800^{\circ} \mathrm{C}$ in air for $1 \mathrm{hr}$.

For the evaluation of the electrochemical performance of cathodes, platinum $(\mathrm{Pt})$ paste was painted on the surface of the cathodes as the current collector and on the opposite side of the electrolyte substrate as the counter and reference electrodes, respectively, followed by baking at $850{ }^{\circ} \mathrm{C}$ for $2 \mathrm{hrs}$. The gap between the circular-shaped counter electrode and the ring-shaped reference electrode was at least three times larger than the thickness of electrolyte substrate. Pt mesh was used as current collector. Electrochemical impedance spectroscopy was obtained at $750{ }^{\circ} \mathrm{C}$ and open circuit in air, by using an impedance/gain phase analyzer (Solartron SI 1260) and an electrochemical interface (Solartron SI 1287) in a frequency range between $0.1 \mathrm{~Hz}$ and $100 \mathrm{kHz}$ with signal amplitude of $10 \mathrm{mV}$. Electrode ohmic resistance $\left(R_{0}\right)$ was determined from the high frequency intercept of the impedance curve at the real axis and the electrode polarization resistance $\left(R_{\mathrm{p}}\right)$ was directly obtained from the difference of the low and high frequency intercepts. The phases in the impregnated LSCF-GDC cathodes were characterized by an X' Pert PRO X-ray diffractometer (XRD). A Sirion 200 field emission scanning electron microscope (SEM) was employed for microstructure examinations of cathodes. The surface chemistry of cathodes was examined by a VG Multilab 2000 X-ray photoelectron spectroscopy (XPS). 


\section{Results and discussion}

\subsection{Phase composition}

Figure 1 shows XRD patterns of the cells with LSCF-GDC composite cathodes fabricated by impregnation before and after $500 \mathrm{hrs}$ of testing at $750{ }^{\circ} \mathrm{C}$ in air. The detection of LSCF peaks in the impregnated LSCF-GDC indicates the formation of LSCF perovskite phase after heat treatment at $800{ }^{\circ} \mathrm{C}$. The XRD patterns of the LSCF-GDC composite cathodes before and after testing are very similar, indicating that there is no phase change after testing at $750{ }^{\circ} \mathrm{C}$ for $500 \mathrm{hrs}$. There are no other phases in the XRD patterns, indicating no solid reaction between the LSCF and GDC during the preparation of the cell and after testing at $750{ }^{\circ} \mathrm{C}$ for $500 \mathrm{hrs}$. The peaks of YSZ phases in XRD patterns are from the YSZ electrolytes. This is different from the cells with LSCF cathodes and YSZ electrolytes, in which the solid reaction at the interface occurs at such high temperatures [32].

\subsection{Electrochemical performance}

Figure 2 is the impedance curves of LSCF-GDC cathodes measured at $750{ }^{\circ} \mathrm{C}$ and open circuit in air. The impedance responses are characterized by an inductance loop at high frequencies, which is mainly induced by contact Pt wires and the high temperature furnace wires $[33,34]$. The electrode impedance for the $\mathrm{O}_{2}$ reduction reaction increases with the time at $750{ }^{\circ} \mathrm{C}$. As shown in Figure $2 \mathrm{a}, R_{\mathrm{p}}$ increases from 0.48 to $0.79 \Omega \mathrm{cm}^{2}$, and $R_{\mathrm{o}}$ increases from 2.27 to $2.36 \Omega \mathrm{cm}^{2}$ after tested for $192 \mathrm{hrs}$ at $750{ }^{\circ} \mathrm{C}$. The increase in $R_{\mathrm{p}}$ is $0.31 \Omega \mathrm{cm}^{2}$, and that of $R_{\mathrm{o}}$ is $0.09 \Omega \mathrm{cm}^{2}$, demonstrating that performance degradation of LSCF-GDC cathodes is caused by both electrode polarization and ohmic losses.

The change in the electrode impedance for the reaction on the impregnated LSCF-GDC 
composite cathodes is remarkable after testing for $500 \mathrm{hrs}$ (see Figure 2b). There is significant increase in both $R_{p}$ and $R_{o} ; R_{\mathrm{p}}$ increases from 0.38 to $0.83 \Omega \mathrm{cm}^{2}$, and $R_{\mathrm{o}}$ increases from 1.79 to $2.14 \Omega \mathrm{cm}^{2}$ after $500 \mathrm{hrs}$ testing at $750{ }^{\circ} \mathrm{C}$. The increase in $R_{\mathrm{p}}$ is $0.45 \Omega \mathrm{cm}^{2}$, which is $118 \%$ of the value before the testing and substantially higher than $13 \%$ increase in the electrode polarization resistance reported on screen printed LSCF cathode after $500 \mathrm{hrs}$ testing at $750{ }^{\circ} \mathrm{C}[10]$. This indicates that degradation rate of nano-structured LSCF-GDC cathode is much higher than conventional LSCF cathodes.

\subsection{Microstructure}

The microstructure of LSCF-GDC cathodes heat-treated at $750{ }^{\circ} \mathrm{C}$ was examined by SEM and the results are shown in Figure 3. The average size of LSCF particles of as-prepared cathode is $86 \mathrm{~nm}$ (Figure 3a) and remains more or less the same during the first $200 \mathrm{hrs}$ of aging (Figure 3b, c). However, the size of LSCF nanoparticles increases to 109 and $125 \mathrm{~nm}$ after 300 and 400 hrs testing (Figure 3d and e), respectively. After testing for 500 hrs, the size of LSCF nanoparticles increases to $130 \mathrm{~nm}$ (Figure 3f). Coarsening causes agglomeration of LSCF nanoparticles and reduces the three-phase boundary (TPB) and the electrochemical activity of cathodes [11]. Agglomeration also decreases the porosity of impregnated LSCF-GDC cathodes and affects the mass transfer process of the oxygen reduction reaction associated with the adsorption and diffusion of oxygen at the gas/cathode interface and the surface diffusion of the oxygen species[35]. This in turn will increase the electrode polarization resistance for the $\mathrm{O}_{2}$ reduction reaction, consistent with the significant increase of $R_{\mathrm{p}}$ of impregnated LSCF-GDC cathodes after testing for $500 \mathrm{hrs}$. The results demonstrate that coarsening of LSCF nanoparticles plays a major role on the performance degradation of 
LSCF-GDC cathodes. Thus, the higher degradation rate of nano-structured LSCF-GDC cathode than that of the conventional LSCF cathodes is most likely due to the high grain growth of impregnated LSCF nanoparticles.

Agglomeration of LSCF nanoparticles could also lead to the reduced interconnectivity between LSCF nanoparticles and the reduction in the connection between electronic conducting LSCF particles would result in the increase of the resistance for the electron and charge transfer of the reaction on LSCF-GDC electrodes. This appears to be consistent with the significant increase in the electrode ohmic resistance as shown in Figure 2. $R_{\mathrm{o}}$ increases with the testing time. As shown in Fig.1, interaction between GDC and LSCF nanoparticles at testing temperature of $750{ }^{\circ} \mathrm{C}$ would be negligible. Thus, the coarsening of LSCF nanoparticles also contributes to the ohmic losses of the impregnated LSCF-GDC cathodes after 500 hrs testing.

\subsection{Surface chemistry}

Figure 4 is the XPS spectra of the La $3 d$, Sr 3d, Co $2 p$ and Fe $2 p$ peaks of the infiltrated LSCF-GDC cathodes before and after testing at $750{ }^{\circ} \mathrm{C}$ in air for $500 \mathrm{hrs}$. It can be seen that there is no obvious variation in the binding energies of $\mathrm{Sr} 3 \mathrm{~d}$ and Fe $2 \mathrm{p}$. In the case of La $3 \mathrm{~d}_{5 / 2}$, the binding energy is $833.76 \mathrm{eV}$ for the as-prepared cathodes, and changes to $833.41 \mathrm{eV}$ after testing, showing that the valence of La does not change significantly and corresponding to $\mathrm{La}^{3+}$ in LSCF lattice[36]. Visible change for the cathodes before and after testing at $750{ }^{\circ} \mathrm{C}$ for $500 \mathrm{hrs}$ was found in the binding energy of Co 2p. The XPS spectra of Co $2 \mathrm{p}$ are doublets including a main peak at ca. $780.0 \mathrm{eV}$ accompanied by a satellite shoulder at ca. $795.5 \mathrm{eV}$ [37]. There is a pronounced shift of the Co $2 \mathrm{p}_{3 / 2}$ peak from $780.33 \mathrm{eV}$ towards lower binding 
energy of $779.54 \mathrm{eV}$ after testing for $500 \mathrm{hrs}$. Though the species of $\mathrm{Co}^{2+}$ and $\mathrm{Co}^{3+}$ are difficult to distinguish[13], their valence variation can be qualitatively determined. The peak of Co $2 \mathrm{p}_{3 / 2}$ at $780.33 \mathrm{eV}$ with another small peak at ca. $785.5 \mathrm{eV}$ corresponds to $\mathrm{Co}^{2+}$, indicating that $\mathrm{Co}$ is predominantly $\mathrm{Co}^{2+}[38,39]$ in the as-prepared LSCF-GDC cathodes. After testing at $750{ }^{\circ} \mathrm{C}$ for $500 \mathrm{hrs}$, the shift to lower binding energy of Co $2 \mathrm{p}_{3 / 2}$ implies the increase of $\mathrm{Co}^{3+}$ content on the surface. This appears to be supported by the relatively high atomic percentage of cobalt after the testing, $19.65 \%$, as compared to $10.66 \%$ before the test, as shown in Table 1.

The molar ratio of $\mathrm{La} / \mathrm{Sr}$ is 0.31 before testing, increased to 0.58 after testing for $500 \mathrm{hrs}$. The result shows that the atomic concentration of $\mathrm{La}$ on the surface of cathodes increases after testing at $750{ }^{\circ} \mathrm{C}$ in air. Similarly, the molar ratio of $\mathrm{Co} / \mathrm{Fe}$ is 0.35 before testing, and increases significantly to 0.82 after testing. The enrichment of Co on the surface indicated the depletion of Co in the bulk and on the formation of cobalt oxides may inhibit the surface diffusion process, thus decreasing the electrocatalytic activity of cathodes. Though the nature of the surface composition and species could not be identified with high degree of confidence, such change in the surface composition would be detrimental to the electrocatalytic activity of the LSCF-GDC electrodes, as indicated by the significant increase in the $\mathrm{R}_{\mathrm{p}}$ for the $\mathrm{O}_{2}$ reduction reaction on infiltrated LSCF-GDC electrodes.

\subsection{Effect of impregnated MgO and LNF}

$\mathrm{MgO}$ and LNF were incorporated into the LSCF-GDC cathodes as an additive in order to improve the stability of the cathodes. Figure 5 is the impedance curves for the $\mathrm{O}_{2}$ reduction reaction on MgO-LSCF-GDC composite cathodes before and after testing at $750{ }^{\circ} \mathrm{C}$ for 500 
hrs. After testing for $500 \mathrm{hrs}, R_{\mathrm{p}}$ of the cathode is $1.06 \Omega \mathrm{cm}^{2}$, very close to $R_{\mathrm{p}}$ of $1.07 \Omega \mathrm{cm}^{2}$ before the testing. The result indicates that the incorporation of $\mathrm{MgO}$ significantly enhances the performance stability of nano-structured LSCF-GDC composite cathodes. However, $R_{\mathrm{o}}$ of LSCF-GDC cathode with $\mathrm{MgO}$ addition is to $6.44 \Omega \mathrm{cm}^{2}$ after testing for $500 \mathrm{hrs}$, higher than $4.85 \Omega \mathrm{cm}^{2}$ before the testing. The increase in $R_{\mathrm{o}}$ is $1.59 \Omega \mathrm{cm}^{2}$, significantly higher than 0.35 $\Omega \mathrm{cm}^{2}$ obtained on LSCF-GDC composite cathodes tested under identical conditions. The significantly high electrode resistance is most likely due to the poor conductivity of impregnated $\mathrm{MgO}$ [40]. The reason for the significantly increased $\mathrm{R}_{\mathrm{o}}$ is not clear at the moment, but the formation of dense $\mathrm{MgO}$ film on the surface of LSCF particles due to the coarsening may be responsible for the observed increase in $\mathrm{R}_{\mathrm{o}}$ after testing at $750^{\circ} \mathrm{C}$ for 500 hrs.

Figure 6 is the SEM of the MgO-LSCF-GDC composite cathodes before and after testing at $750{ }^{\circ} \mathrm{C}$. Before testing, the average size of LSCF and $\mathrm{MgO}$ particles was $82 \mathrm{~nm}$ and distributed uniformly on the surface of GDC scaffold (Figure 6a). After testing at $750{ }^{\circ} \mathrm{C}$, the change in the microstructure of the MgO-LSCF-GDC cathodes is very small. For example, after testing for $500 \mathrm{hrs}$ at $750{ }^{\circ} \mathrm{C}$ in air, the particle size of LSCF phase is $89 \mathrm{~nm}$, (Figure $6 \mathrm{~d}$ ), very close to $82 \mathrm{~nm}$ before the test. This indicates that coarsening of LSCF particles is suppressed by the addition of $\mathrm{MgO}$ phase.

LNF cathode has been shown with good performance stability $[9,41]$. In the present study, LNF phase was also introduced into LSCF-GDC cathodes as performance stabilizer to suppress degradation. Figure 7 shows the impedance curves of LSCF-GDC cathodes with LNF measured at $750{ }^{\circ} \mathrm{C}$ and open circuit in air. After testing for $500 \mathrm{hrs}, R_{\mathrm{p}}$ increased from 
0.27 to $0.4 \Omega \mathrm{cm}^{2}$, an increase in $\mathrm{R}_{\mathrm{p}}$ by $48 \%$, significantly lower than $118 \%$ increase of polarization resistance observed for the LSCF-GDC cathode without introduction of LNF. This indicates that the addition of LNF phase also enhances the stability of the LSCF-GDC composite cathodes. On the other hand, $R_{\mathrm{o}}$ increased from 2.33 to $2.89 \Omega \mathrm{cm}^{2}$, and the increase rate of $R_{\mathrm{o}}$ is similar to the cathode without introduction of LNF. Different to $\mathrm{MgO}$, LNF has excellent conductivity and electrocatalytic activity for the $\mathrm{O}_{2}$ reduction reactions [41, 42]. Thus the introduction of LNF can improve the performance stability as well as maintain high conductivity and electrochemical activity for the nano-structured LSCF-GDC cathode.

The SEM micrographs of LNF-LSCF-GDC cathodes before and after testing are shown in Figure 8. Before testing, the average size of infiltrated LSCF/LNF nanoparticles is $83 \mathrm{~nm}$, distributed uniformly on the surface of porous GDC scaffold (Figure 8a). After testing at 750 ${ }^{\circ} \mathrm{C}$ for $100 \mathrm{hrs}$, the size of LSCF/LNF particles is $\sim 91 \mathrm{~nm}$ (Figure $8 \mathrm{~b}$ ) and after testing for $500 \mathrm{hrs}$, the LSCF/LNF nanoparticles are in the range of $92 \mathrm{~nm}$ (Figure 8d), indicating the high stability of LSCF/LNF nanoparticles. SEM results clearly indicate that the coarsening of LSCF nanoparticles is suppressed by the addition of LNF phase, similar to that of the added $\mathrm{MgO}$ phase (see Fig.6).

\section{Conclusions}

Performance degradation of LSCF-GDC cathodes prepared by impregnation was investigated. The electrochemical impedance spectroscopy and microstructure analysis reveal that coarsening of LSCF particles is the origin of the increased polarization and ohmic losses. Agglomeration of LSCF nanoparticles reduces the active three phase boundary areas and 
decreases the electrical contacts between LSCF nanoparticles. The microstructure changes play an important role in the performance degradation of LSCF-GDC cathode during testing at $750{ }^{\circ} \mathrm{C}$. XPS analysis shows changes in the surface composition of the infiltrated LSCF-GDC cathodes after testing for $500 \mathrm{hrs}$ and such changes could also contribute to the degradation of the electrocatalytic activity of the cathodes. Addition of $\mathrm{MgO}$ or LNF phases can suppress performance degradation by inhibiting the coarsening of LSCF nanoparticles. The results indicate that the introduction of LNF phase into LSCF-GDC cathodes is most effective to improve the performance stability as well as maintain relatively high conductivity and electrochemical activity of the infiltrated nano-structured LSCF-GDC cathodes.

\section{Acknowledgements}

This work was financially supported by the National Natural Science foundation of China (U1134001), the National "863" project of China (2011AA050702) and Australia Research Council (LP110200281). XRD and SEM examinations were assisted by the Analytical and Testing Center of Huazhong University of Science and Technology.

\section{References:}

[1] S.P. Jiang, Solid State Ionics 146 (2002) 1-22.

[2] A. Mai, V.A.C. Haanappel, S. Uhlenbruck, F. Tietz, D. Stover, Solid State Ionics 176 (2005) 1341-1350.

[3] W.G. Wang, M. Mogensen, Solid State Ionics 176 (2005) 457-462.

[4] J.M. Bae, B.C.H. Steele, Solid State Ionics 106 (1998) 247-253.

[5] D. Beckel, U.P. Muecke, T. Gyger, G. Florey, A. Infortuna, L.J. Gauckler, Solid State Ionics 178 (2007) 407-415.

[6] C.J. Fu, K.N. Sun, N.Q. Zhang, X.B. Chen, D.R. Zhou, Electrochim. Acta 52 (2007) 
4589-4594.

[7] A. Lanzini, P. Leone, M. Santarelli, P. Asinari, M. Cali, R. Borchiellini, J. Fuel Cell Sci. Technol. 6 (2009) 011020 1-14.

[8] B.C.H. Steele, J.M. Bae, Solid State Ionics 106 (1998) 255-261.

[9] H. Yokokawa, H. Tu, B. Iwanschitz, A. Mai, J. Power Sources 182 (2008) 400-412.

[10] S.P. Simner, M.D. Anderson, M.H. Engelhard, J.W. Stevenson, Electrochem. Solid State Lett. 9 (2006) A478-A481.

[11] M. Shah, P.W. Voorhees, S.A. Barnett, Solid State Ionics 187 (2011) 64-67.

[12] S.P. Jiang, J. Li, in: J.W. Fergus, R. Hui, X.G. Li, D.P. Wilkinson, J.J. Zhang (Eds.), Solid oxide Fuel Cells: Materials Properties and Performance, CRC Press, Boca Raton, 2009, pp. 131-177.

[13] E. Bucher, W. Sitte, F. Klauser, E. Bertel, Solid State Ionics 191 (2011) 61-67.

[14] Z.P. Li, M. Toshiyuki, G.J. Auchterlonie, J. Zou, D. John, ACS Appl. Mater. Interfaces 3 (2011) 2772-2778.

[15] D. Oh, D. Gostovic, E.D. Wachsman, J. Mater. Res. 27 (2012) 1992-1999.

[16] S. Lee, N. Miller, K. Gerdes, J. Electrochem. Soc. 159 (2012) F301-F308.

[17] Y.J. Leng, S.H. Chan, Q.L. Liu, Int. J. Hydrogen Energy 33 (2008) 3808-3817.

[18] F. Qiang, K.N. Sun, N.Q. Zhang, X.D. Zhu, S.R. Le, D.R. Zhou, J. Power Sources, 168 (2007) 338-345.

[19] F.C. Fonseca, S. Uhlenbruck, R. Nedelec, H.P. Buchkremer, J. Power Sources 195 (2010) 1599-1604.

[20] R. Knibbe, J. Hjelm, M. Menon, N. Pryds, M. Sogaard, H.J. Wang, K. Neufeld, J. Am. Ceram. Soc. 93 (2010) 2877-2883.

[21] J.M. Vohs, R.J. Gorte, Adv. Mater. 21 (2009) 943-956.

[22] S.P. Jiang, Int. J. Hydrogen Energy 37 (2012) 449-470.

[23] Z.Y. Jiang, C.R. Xia, F.L. Chen, Electrochim. Acta 55 (2010) 3595-3605.

[24] M. Shah, S.A. Barnett, Solid State Ionics 179 (2008) 2059-2064.

[25] J. Chen, F.L. Liang, L.N. Liu, S.P. Jiang, B. Chi, J. Pu, J. Li, J. Power Sources 183 (2008) 586-589.

[26] J. Chen, F.L. Liang, D. Yan, J. Pu, B. Chi, S.P. Jiang, J. Li, J. Power Sources 195 (2010) 5201-5205.

[27] J. Chen, F.L. Liang, B. Chi, J. Pu, S.P. Jiang, J. Li, J. Power Sources 194 (2009) 275-280.

[28] Y.H. Liu, B. Chi, J. Pu, J. Li, Int. J. Hydrogen Energy 37 (2012) 4388-4393.

[29] Y. Liu, S. Hashimoto, H. Nishino, K. Takei, M. Mori, J. Power Sources 164 (2007) $56-64$.

[30] F.L. Liang, J. Chen, S.P. Jiang, B. Chi, J. Pu, J. Li, Electrochem. Solid State Lett. 11 (2008) B213-B216.

[31] Z.Y. Jiang, L. Zhang, K. Feng, C.R. Xia, J. Power Sources 185 (2008) 40-48.

[32] A. Mai, M. Becker, W. Assenmacher, F. Tietz, D. Hathiramani, E. Ivers-Tiffee, D. Stover, W. Mader, Solid State Ionics 177 (2006) 1965-1968.

[33] F.L. Liang, J. Chen, J.L. Cheng, S.P. Jiang, T.M. He, J. Pu, J. Li, Electrochem. Commun. 10 (2008) 42-46.

[34] B. Liu, H. Muroyama, T. Matsui, K. Tomida, T. Kabata, K. Eguchi, J. Electrochem. Soc. 
157 (2010) B1858-B1864.

[35] F.L. Liang, J. Chen, B. Chi, J. Pu, S.P. Jiang, J. Li, J. Power Sources 196 (2011) 153-158. [36] P.A.W. van der Heide, Surf. and Interface Anal. 33 (2002) 414-425.

[37] C.D. Wagner, W.M. Riggs, L.E. Davis, J.F. Moulder, G.E. Muilenberg, in: Handbook of X-ray photoelectron spectroscopy, Perkin-Elmer Corporation, Minnesota, 1981, pp. 29-167. [38] T. Choudhury, S.O. Saied, J.L. Sullivan, A.M. Abbot, J. Phys. D-Appl. Phys. 22 (1989) 1185-1195.

[39] C.R. Brundle, T.J. Chuang, D.W. Rice, Surf. Sci. 60 (1976) 286-300.

[40] Y. Shiratori, F. Tietz, H.P. Buchkremer, D. Stover, Solid State Ionics 164 (2003) 27-33.

[41] H. Orui, K. Watanabe, R. Chiba, M. Arakawa, J. Electrochem. Soc. 151 (2004) A1412-A1417.

[42] E. Niwa, C. Uematsu, E. Miyashita, T. Ohzeki, T. Hashimoto, Solid State Ionics 201 (2011) 87-93. 


\section{Figure captions}

1. XRD patterns of the nano-structured LSCF-GDC cathodes: (a) as prepared and (b) tested at $750{ }^{\circ} \mathrm{C}$ and open circuit in air for $500 \mathrm{hrs}$.

2. Electrochemical impedance spectra of LSCF-GDC cathodes measured at $750{ }^{\circ} \mathrm{C}$ and open circuit in air for (a) 0 to $192 \mathrm{hrs}$ and (b) $500 \mathrm{hrs}$.

3. SEM micrographs of fractured cross-sections of LSCF-GDC cathodes after testing at $750{ }^{\circ} \mathrm{C}$ and open circuit in air for (a) 0, (b) 100, (c) 200, (d) 300, (e) 400, (f) $500 \mathrm{hrs}$.

4. XPS spectra of the La 3d, Sr 3d, Co 2p, Fe 2p peaks of LSCF-GDC cathodes before (curve a, square symbols) and after (curve b, circle symbols) test in air for $500 \mathrm{hrs}$ at $750{ }^{\circ} \mathrm{C}$ under open circuit.

5. Electrochemical impedance spectra of LSCF-GDC cathodes with $\mathrm{MgO}$ as stabilizer, measured at $750{ }^{\circ} \mathrm{C}$ before and after testing under open circuit in air for $500 \mathrm{hrs}$.

6. SEM micrographs of fractured cross-sections of LSCF-GDC cathodes with $\mathrm{MgO}$ as stabilizer after testing at $750{ }^{\circ} \mathrm{C}$ and open circuit in air for (a) 0 , (b) 100 , (c) 400, (d) 500 hrs.

7. Electrochemical impedance spectra of LSCF-GDC cathodes with LNF as stabilizer, measured at $750{ }^{\circ} \mathrm{C}$ before and after testing under open circuit in air for $500 \mathrm{hrs}$.

8. SEM micrographs of fractured cross-sections of LSCF-GDC cathodes with LNF as stabilizer after testing at $750{ }^{\circ} \mathrm{C}$ and open circuit in air for (a) 0 , (b) 100 , (c) 400, (d) 500 hrs. 


\section{Table 1.}

Binding energy and relative atomic concentration determined by XPS spectra for LSCF-GDC cathodes before and after test in air for $500 \mathrm{hrs}$ at $750{ }^{\circ} \mathrm{C}$ under open circuit.

\begin{tabular}{|c|c|c|c|c|}
\hline \multirow{2}{*}{ Element } & \multicolumn{2}{|c|}{ Before Test } & \multicolumn{2}{c|}{ After Test for 500h } \\
\cline { 2 - 5 } & Binding energy(eV) & at.\% & Binding energy(eV) & at.\% \\
\hline La 3d 5/2 & 833.76 & 13.98 & 833.41 & 20.67 \\
Sr 3d 5/2 & 133.23 & 45.06 & 133.23 & 35.81 \\
Co 2p 3/2 & 780.33 & 10.66 & 779.54 & 19.65 \\
Fe 2p 3/2 & 709.76 & 30.30 & 709.70 & 23.87 \\
\hline
\end{tabular}




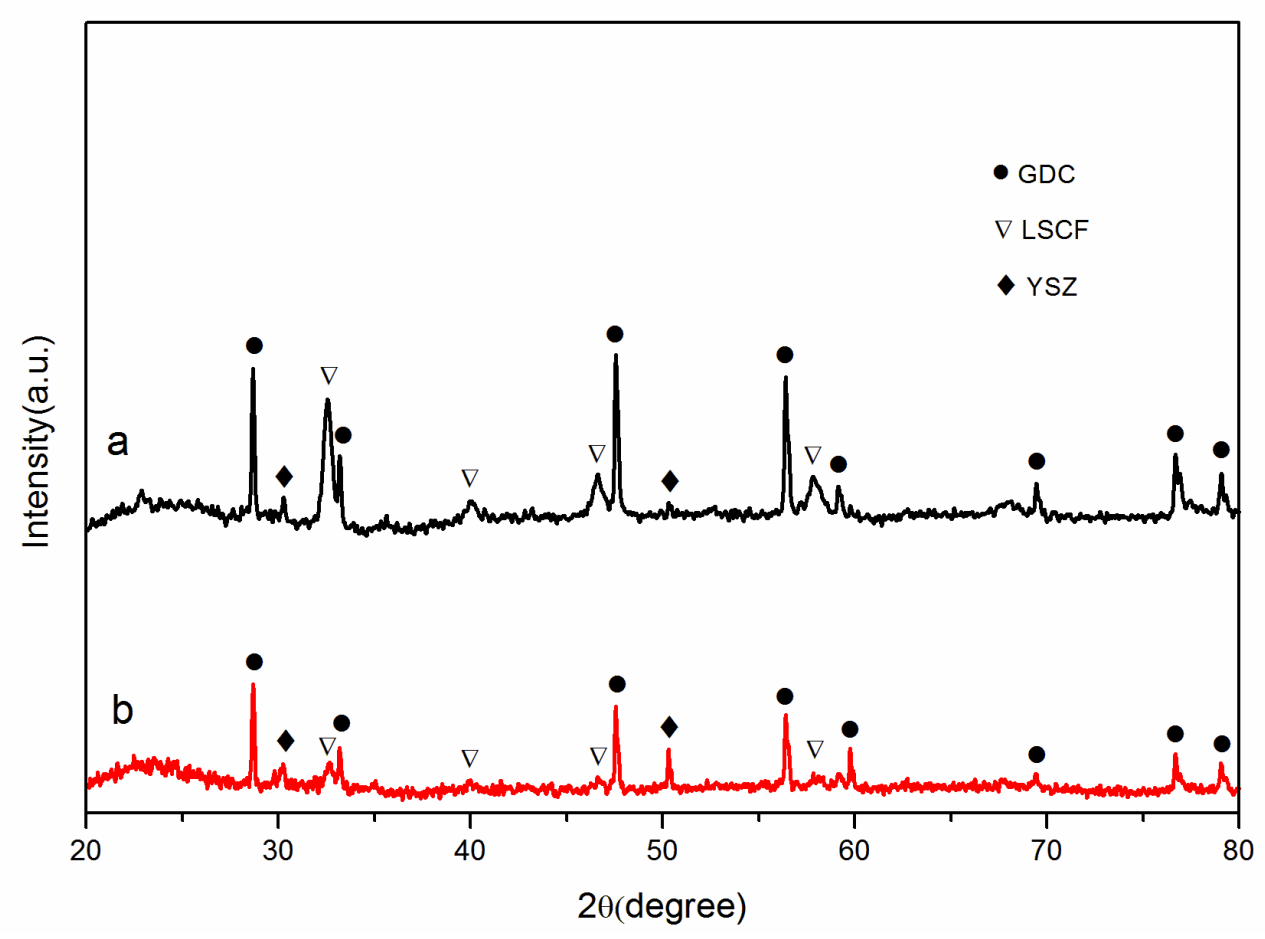

Figure 1. 


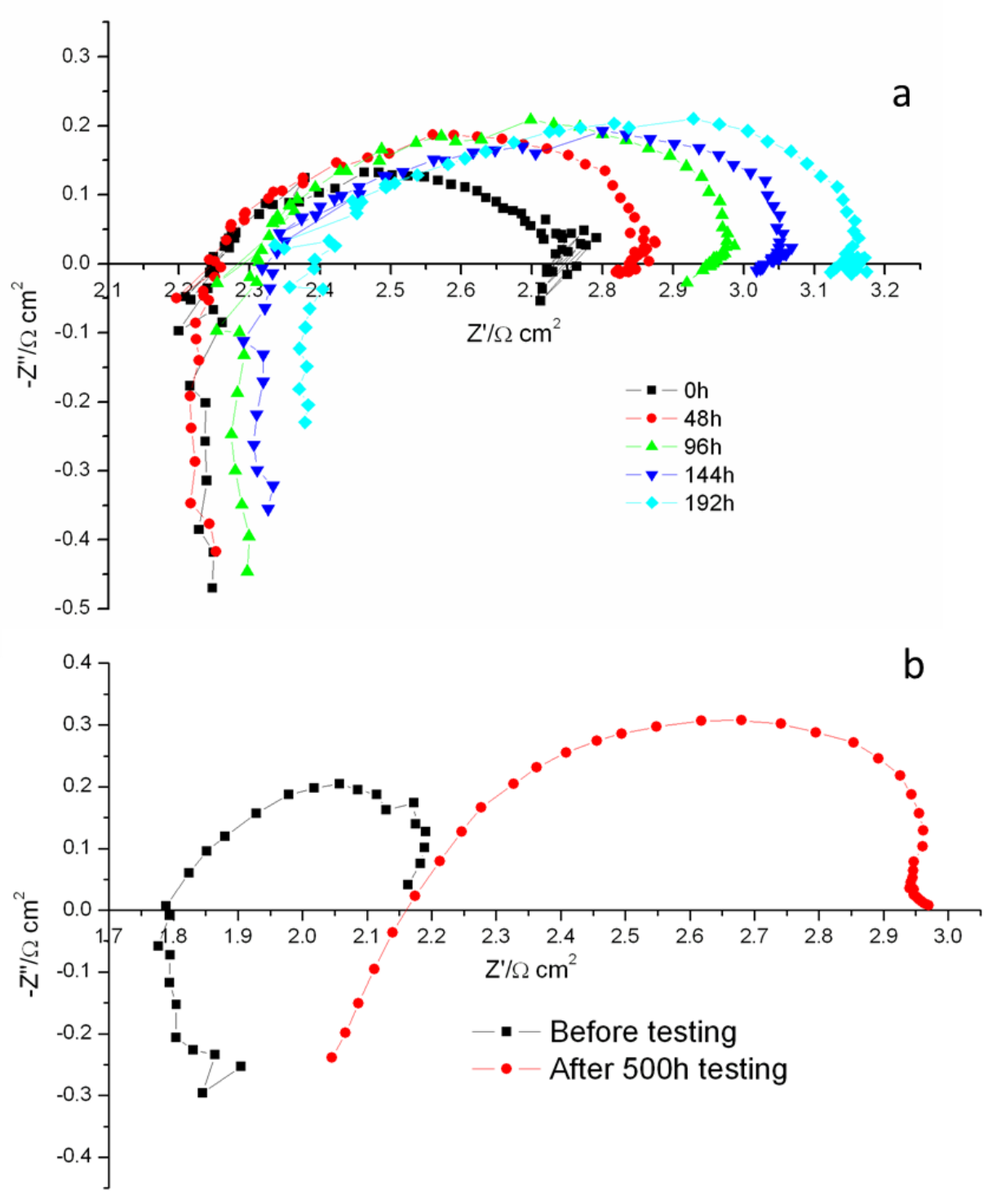

Figure 2. 

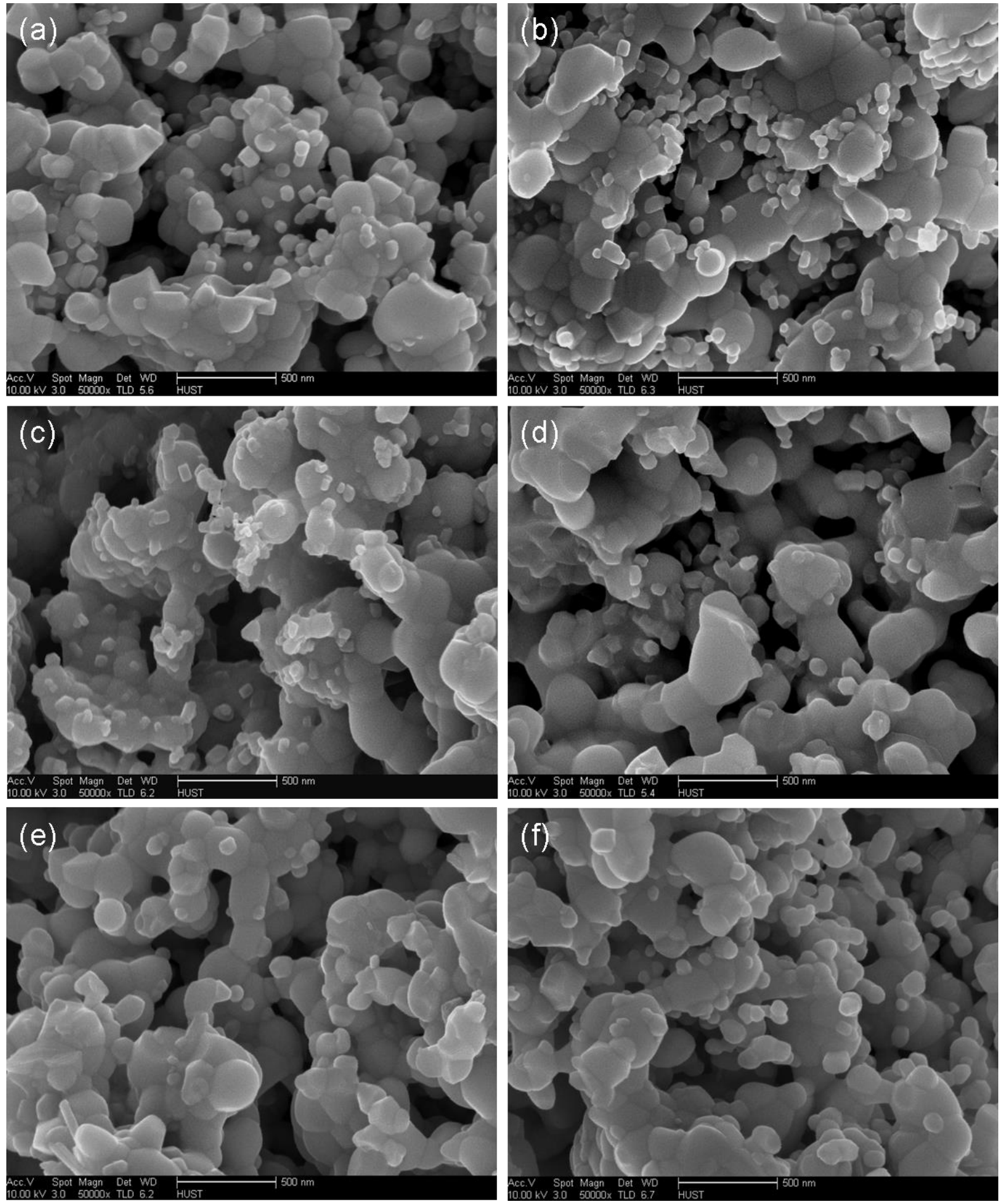

Figure 3. 

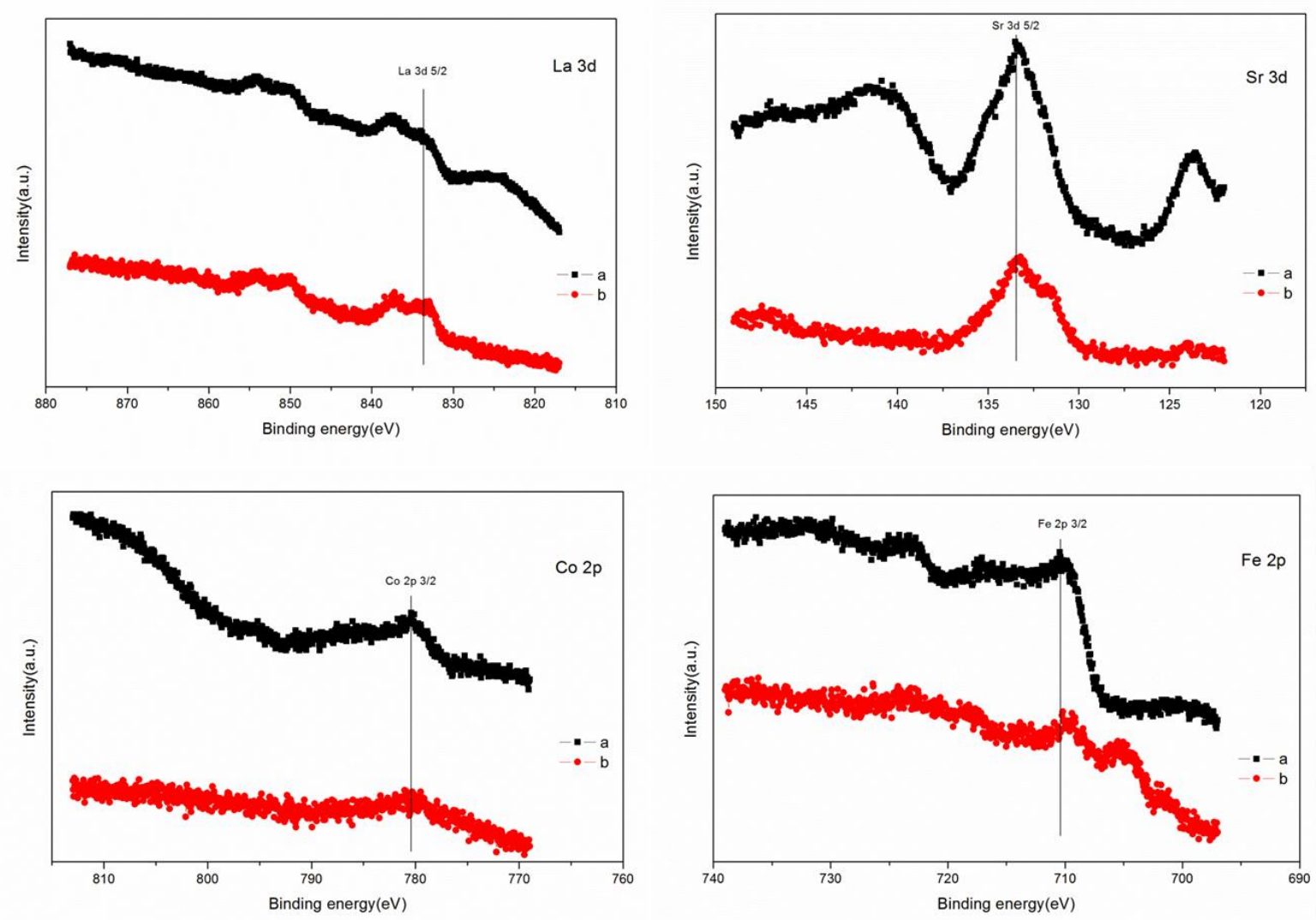

Figure 4. 


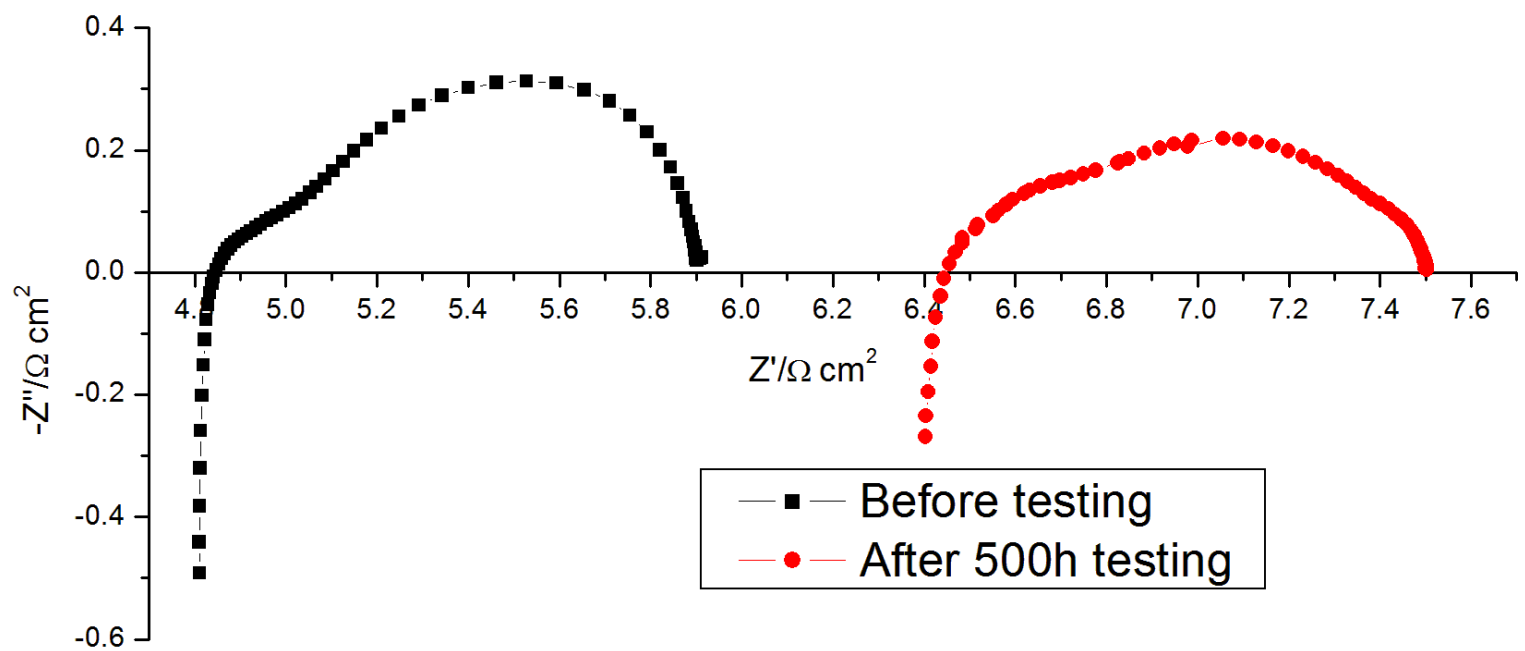

Figure 5. 

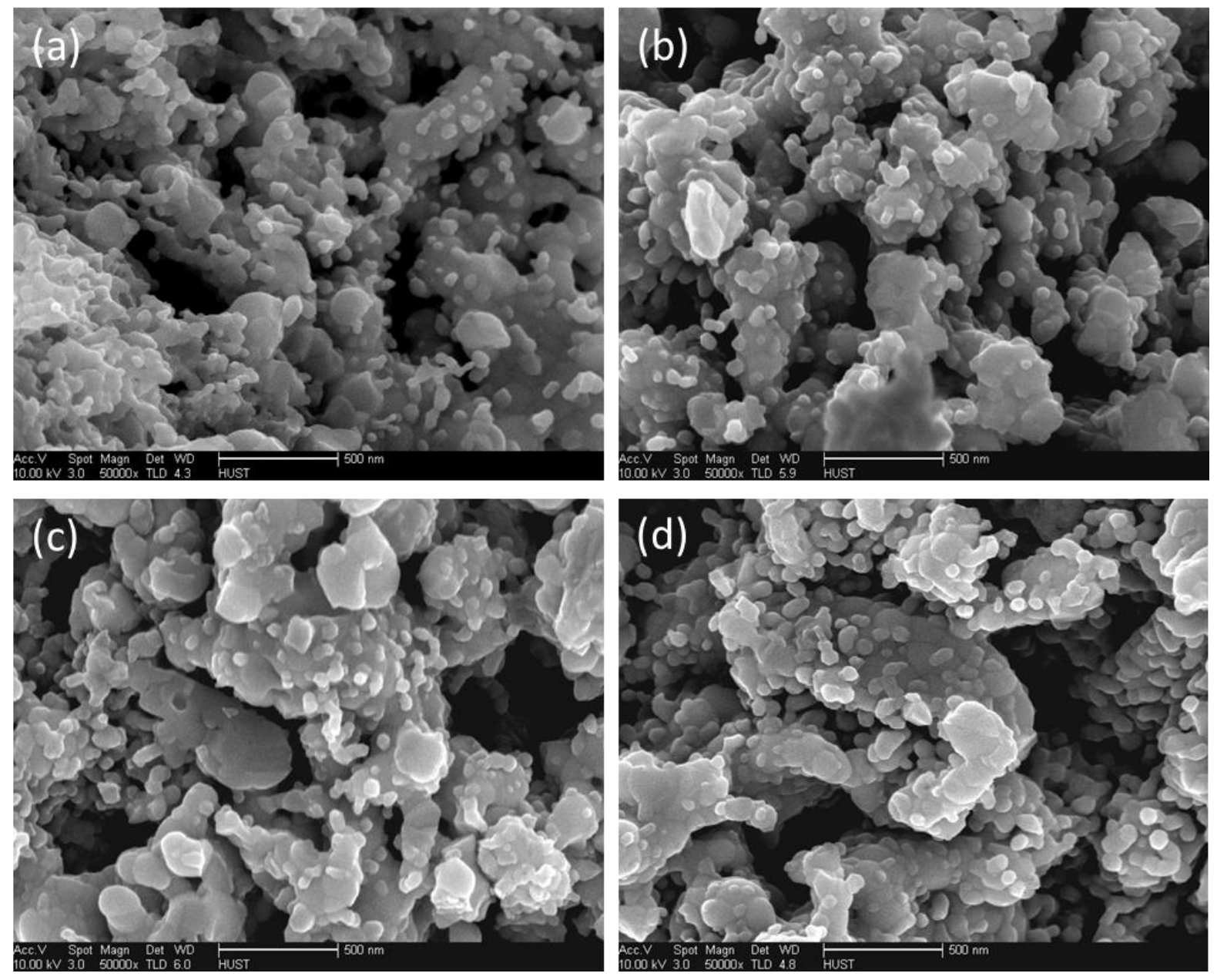

Figure 6. 


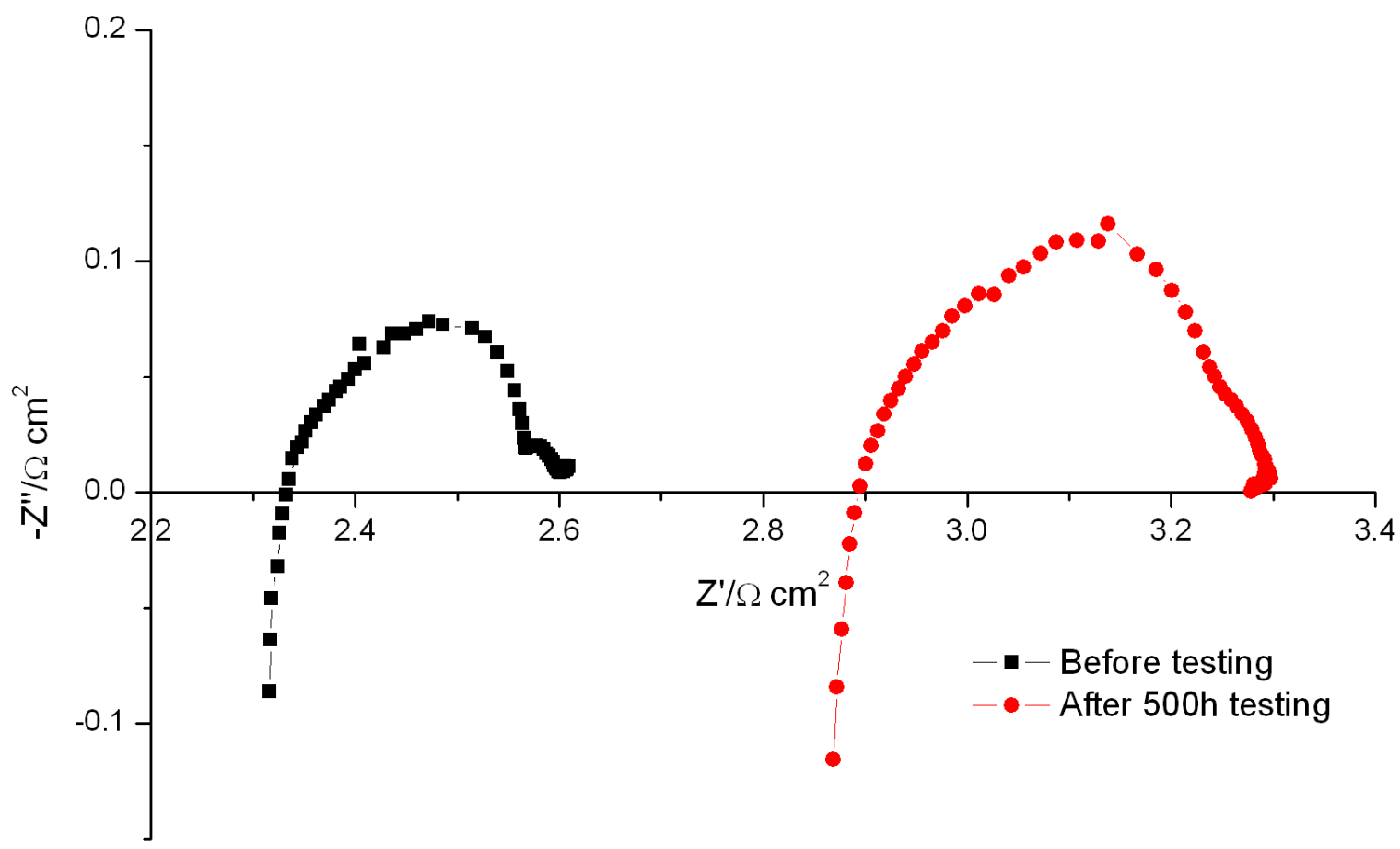

Figure 7. 

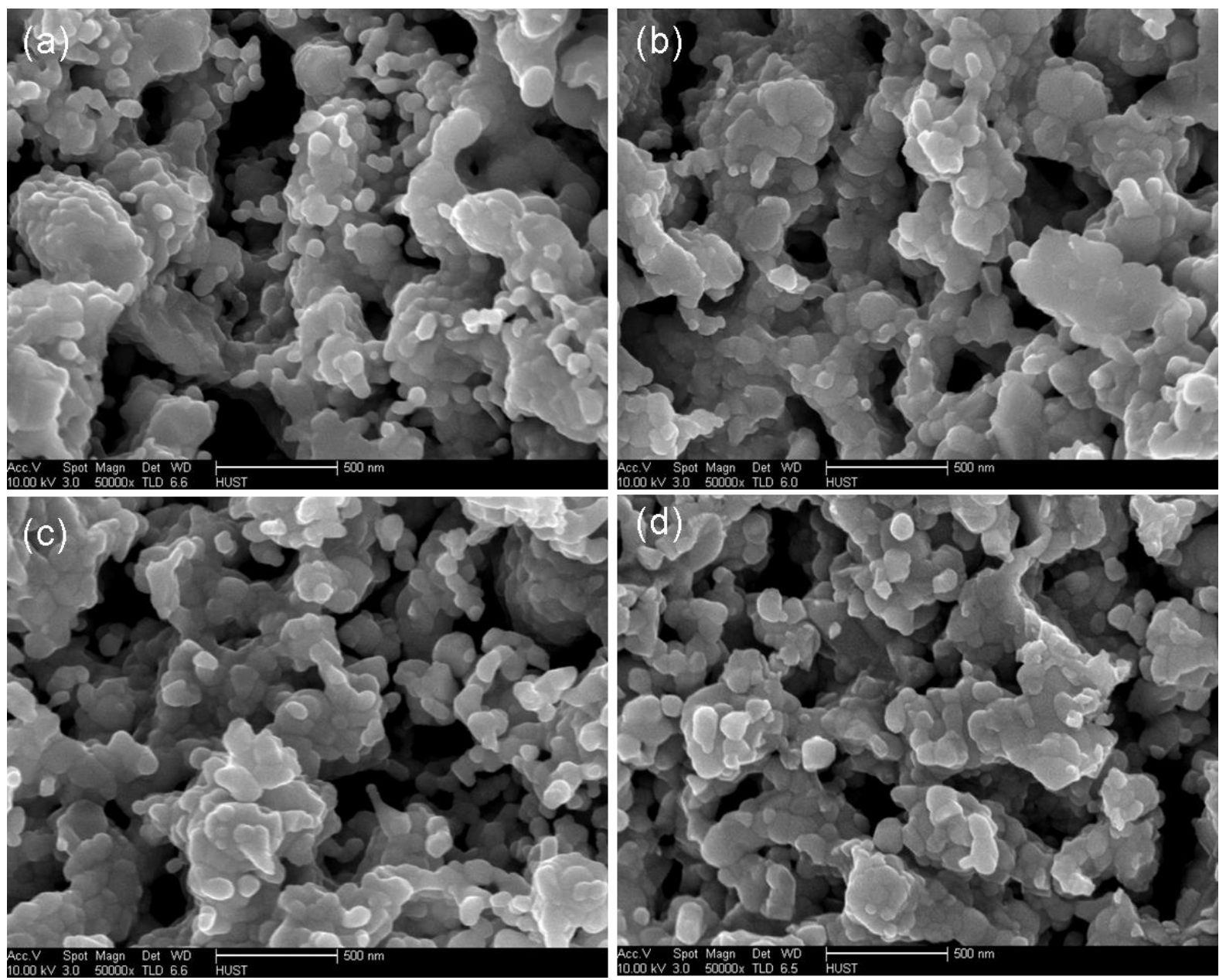

Figure 8. 